\title{
Genetic engineering of the $\beta$-oxidation pathway in the yeast Yarrowia lipolytica to increase the production of aroma compounds
}

\author{
Anne Groguenin ${ }^{\text {a }}$, Yves Waché ${ }^{\mathrm{a}, *}$, Erandi Escamilla Garcia ${ }^{\mathrm{a}}$, Mario Aguedo ${ }^{\mathrm{a}, 1}$, \\ Florence Husson $^{\mathrm{a}}$, Marie-Thérèse LeDall ${ }^{\mathrm{b}}$, Jean-Marc Nicaud ${ }^{\mathrm{b}}$, Jean-Marc Belin ${ }^{\mathrm{a}}$ \\ a Laboratoire de Microbiologie UMR UB-INRA 1232, ENSBANA, 1, Esplanade Erasme, 21000 Dijon, France \\ ${ }^{\mathrm{b}}$ Laboratoire de Microbiologie et Génétique Moléculaire, INRA-CNRS-INAPG UMR 2585, 78850 Thiverval-Grignon, France
}

Received 5 August 2003; received in revised form 8 December 2003; accepted 20 January 2004

\begin{abstract}
The yeast Yarrowia lipolytica possesses five acyl-CoA oxidases (Aox 1p to 5), the enzyme catalysing the first reaction of $\beta$-oxidation. The understanding of the specific role of each acyl-CoA oxidase is important to construct a yeast strain growing at a good rate and able to produce without degrading the aroma compound $\gamma$-decalactone. In this study we observed that Aox $4 p$ exhibits a slight activity on a broad spectrum of substrates and that it is involved in lactone degradation. We constructed a strain lacking this activity. Its growth was only slightly altered and it produced 10 times more lactone than the wild type in $48 \mathrm{~h}$.
\end{abstract}

(C) 2004 Elsevier B.V. All rights reserved.

Keywords: $\beta$-Oxidation; Hydroxy acids; Acyl-CoA oxidase; $\gamma$-Decalactone

\section{Introduction}

The yeast Yarrowia lipolytica is able to transform ricinoleic acid (a hydroxylated C18 fatty acid) into $\gamma$-decalactone (Fig. 1), a fruity and creamy aroma compound [1]. As most of the yeast able to carry out this biotransformation, it is also able to degrade the produced lactone. Thanks to its exceptional lipid-degrading enzymatic-machinery, this species, which is also used in several processes [2-7], has been chosen as a model to study this degradation. The pathway of biotransformation involves $\beta$-oxidation and requires the lactonisation at the $\mathrm{C} 10$ level (when the hydroxy group is in the $\gamma$-position) (Fig. 1) [1]. Y. lipolytica possesses a five-member family of acyl-CoA oxidases (Aox1p to 5 encoded by POX1 to 5), the enzymes catalysing the first step of $\beta$-oxidation, some of which are long-chain specific (Aox $2 p$ ) [8] or short-chain specific (Aox3p) [9,10], the specificity resulting from only a small number of amino-acids (see Mlíčková et al. in this volume, [11]). The short-chain spe-

\footnotetext{
* Corresponding author. Tel.: +33-3-8039-6680; fax: +33-3-8039-6641.

E-mail address: ywache@u-bourgogne.fr (Y. Waché).

1 Present address: Dep. de Engenheria Biológica, Universidade do Minho, Campus de Gualtar, 4710-057 Braga, Portugal.
}

cific enzyme is involved in the degradation of the lactone (Fig. 1) and therefore genetic constructions have been made to remove its activity from yeast strains [12]. It was thus shown that this enzyme was not the only one involved in the degradation and some of the other acyl-CoA oxidases exhibited activity on short-chain substrates [13]. From the evaluation of the acyl-CoA oxidase activity of the $P O X$-mutants, it was not easy to appreciate the role of the three other acyl-CoA oxidases (Aox 1p, Aox4p and Aox 5p): the deletion of poxl did not seem to modify the activity as if Aox $1 \mathrm{p}$ was inactive towards straight-chained acyl-CoA. The deletion of pox 5 decreased activity on the complete chain-length spectrum whereas the deletion of pox4 exhibited no significant effect. To confirm the activity or inactivity of these enzymes, a construction was made involving the deletion of several acyl-CoA oxidase encoding genes $(\Delta$ pox $2 \Delta$ pox $3 \Delta$ pox 5$)$ and a multicopy insertion of $P O X 2$, the long-chain specific encoding gene [14] but, as the efficiency of the multicopy insertion was low, the constructed strain exhibited an altered growth resulting in a low production and no degradation of $\gamma$-decalactone but whether the absence of detectable degradation was due to a lack of short-chain active acyl-CoA oxidases or to a rate of degradation lower than the rate of production was not determined. 


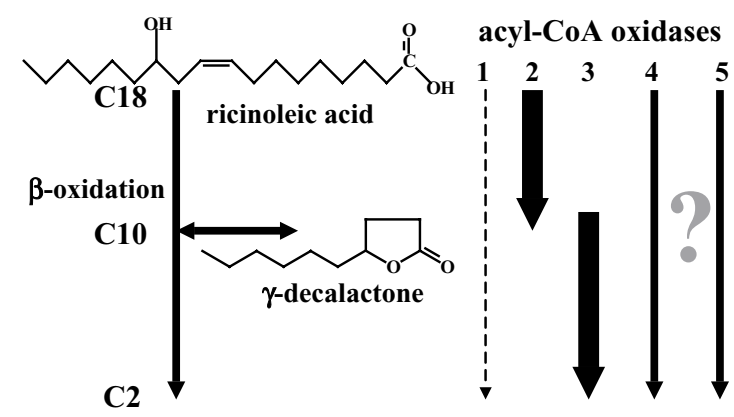

Fig. 1. Schematic representation of the pathway from ricinoleic acid to $\gamma$-decalactone and activities of the acyl-CoA oxidases of $Y$. lipolytica (Aox $1 \mathrm{p}$ to 5).

As the growth rate of mutant strains is very important for industrial application and as this parameter is linked to the number of deletion of genes coding for lipid-degradation-enzymes, it is of fundamental interest to establish the role of each of these enzymes. The goal of the present study was to investigate the effect of Aox $4 p$ and Aox $5 p$ on the degradation of $\gamma$-decalactone and to construct a strain unable to degrade it but able to grow at a rate similar to that of the wild type. Using the same triple disruptant ( $\triangle$ pox $2 \Delta$ pox $3 \Delta$ pox 5 ), a simple copy of $P O X 2$ was added restoring the Ura+ character. With nearly the same genotype as the mutant previously constructed, the phenotype was quite different as the strain was able to grow in a way similar to the wild type but was also able to degrade the lactone produced. These results show that a remaining acyl-CoA oxidase was also able to degrade the lactone and, as Aox $1 \mathrm{p}$ seems inactive, we did the same POX2 addition in a $\Delta$ pox $2 \Delta$ pox $3 \Delta$ pox $4 \Delta$ pox 5 mutant. We obtained a mutant able to grow only a little more slowly than the wild type but producing about 10 times more $\gamma$-decalactone in only $48 \mathrm{~h}$, and this amount did not significantly decrease in $250 \mathrm{~h}$.

\section{Experimental}

\subsection{Strain constructions}

The strain used in this study is $Y$. lipolytica W29 MatA (ATCC 20460, CLIB89) or its derived mutant disrupted for genes coding for acyl-CoA oxidases (POX) [8]. To introduce the uracil auxotrophy into the mutant strain MTL37, the ura3-41 allele from the H222 ura3-41 strain [15] was introduced by transformation and selection of Ura- cells on YNB-5FOA medium as described previously [16] giving rise to strain MTLY40. The various strains are presented in Table 1.

The POX2 and POX3 genes were amplified with oligonucleotides pairs POX2-ATG/POX2-STOP, and POX3-ATG/POX3-STOP, respectively. Plasmid pYEG1 [17] was digested by BlnI and SfiI and ligated with the PCR fragments digested with the same enzymes, giving rise to plasmid pYEG1-POX2 and pYEG1-POX3. Both
Table 1

Names, $P O X$ genotype and growth characteristics of strains of $Y$. lipolytica used in this study

\begin{tabular}{llll}
\hline Strains & Genotype & Aox expressed & Growth \\
\hline W29 & Wild type & None & Normal \\
MTLY36 & Apox2,pox3,pox5 & None & Reduced \\
MTYL37 & Apox2,pox3,pox4,pox5 & None & No growth \\
MTLY40 & Apox2,pox3,pox4,pox5 & None & No growth \\
MTLY36-2P & Apox3,pox5 & Aox2p & Normal \\
MTLY40-2P & Apox3,pox4,pox5 & Aox2p & Normal \\
\hline
\end{tabular}

The growth characteristics (in media containing methyl oleate or methyl ricinoleate as the only source of carbon) are given compared to wild type (normal growth).

expression cassettes were introduced into MTLY36 and MTLY40 by the lithium acetate method [18]. Prior to integration into yeast cells, plasmids were digested by Not I. Ura+ transformants were selected on YNBcas.

\subsection{Culture conditions}

Cells were cultured at $27^{\circ} \mathrm{C}$ in $500 \mathrm{ml}$ baffled Erlenmeyer flasks containing $200 \mathrm{ml}$ medium and agitated at $140 \mathrm{rpm}$ for the lactone production in different environmental conditions. Cells were precultured in a YPD modified medium (glucose, $20 \mathrm{~g} / \mathrm{l}$; trypsic peptone from casein, $20 \mathrm{~g} / \mathrm{l}$, yeast extract, $10 \mathrm{~g} / \mathrm{l}$ ) for $19 \mathrm{~h}$ to the late logarithmic phase then cells were harvested and inoculated to an $A_{600 \mathrm{~nm}}$ of 0.25 (approximately $6.5 \times 10^{6}$ cells $/ \mathrm{ml}$ ) in a medium containing $5 \mathrm{~g} / \mathrm{l}$ methyl ricinoleate (biotransformation medium: methyl ricinoleate (Stéarinerie Dubois, Boulogne, France), 5 g/l; Tween $80,1 \mathrm{~g} / \mathrm{l}$; yeast nitrogen base, $3.35 \mathrm{~g} / \mathrm{l})$.

\subsection{Analysis}

For lactone quantification, $1.5 \mathrm{ml}$ samples were removed from the biotransformation medium. These samples were centrifuged $(10,000 \times g, 5 \mathrm{~min})$ and the supernatant (both aqueous and oil phases) mixed. $\gamma$-Undecalactone (internal standard) was added to reach a final concentration of $100 \mathrm{mg} / \mathrm{l}$ and the mixture was extracted with diethyl ether, in $4 \mathrm{ml}$ glass vials, by shaking for $60 \mathrm{~s}$. The ether phase was analysed in a HP6890 gas chromatograph (Agilent Technologies, Lyon, France) with a HP-INNOWax capillary column (Agilent) $(30.0 \mathrm{~m} \times 320 \mu \mathrm{m} \times 0.25 \mu \mathrm{m})$ with $\mathrm{N}_{2}$ as a carrier gas at a linear flow rate of $4.3 \mathrm{ml} / \mathrm{min}$. The split injector (split ratio, 7.1:1) temperature was set to $250^{\circ} \mathrm{C}$ and that of the FID detector to $300^{\circ} \mathrm{C}$. The oven temperature was programmed to increase from 60 to $145^{\circ} \mathrm{C}$ at a rate of $5^{\circ} \mathrm{C} / \mathrm{min}$ and then to $215^{\circ} \mathrm{C}$ at a rate of $2^{\circ} \mathrm{C} / \mathrm{min}$.

\section{Results and discussion}

\subsection{Growth of Y. lipolytica wild type and pox mutants}

Growth of the various strains in the biotransformation medium is shown in Fig. 2. A $3-4 \mathrm{~h}$ lag phase was 


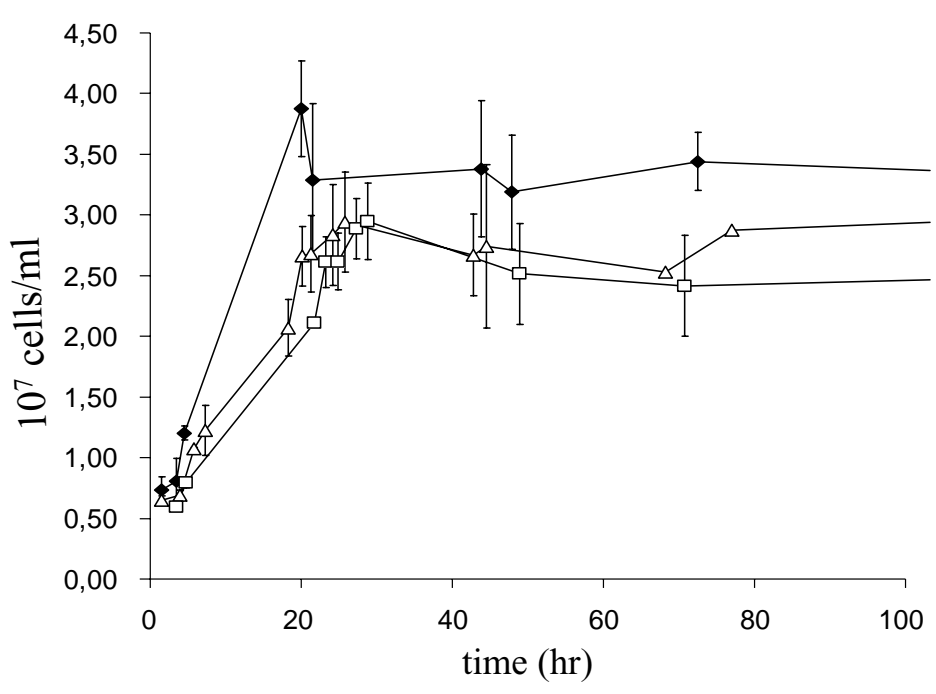

Fig. 2. Growth of $Y$. lipolytica strains in the biotransformation medium (containing methyl ricinoleate as the only carbon source): wild-type W29 ( $\bullet$ ), MTLY36-2P $(\triangle)$ and MTLY40-2P $(\square)$ strains.

observed for all strains. Prior to inoculation of the biotransformation medium, cells were harvested in log-phase from a preculture medium containing glucose as the carbon source. They required thus the complete induction of the 'lipid-degradation machinery'. This takes time since, in $Y$. lipolytica, $\beta$-oxidation occurs in peroxisomes that are inducible compartments [19] and $\beta$-oxidation enzymes are induced and produced in the cytoplasm before being targeted to the peroxisome [20].

After this lag-phase, significant differences appeared between the cells. The wild type (W29) grew rapidly to a value of about $3.5-4 \times 10^{7}$ cells $/ \mathrm{ml}$ in less than $20 \mathrm{~h}$ whereas the MTLY36-2P strain reached its maximum (less than $3 \times$ $10^{7}$ cells $/ \mathrm{ml}$ ) in more than $25 \mathrm{~h}$ and MTLY40-2P in almost $30 \mathrm{~h}$.

The POX genotype has thus no effect on the lag-phase, i.e. on the induction time of the enzymatic machinery, but has a significant effect on the growth rate and on the maximal cell concentration. Methyl ricinoleate is the only source of carbon in the biotransformation medium and $\beta$-oxidation is thus required for growth. Acyl-CoA oxidases catalyse the first reaction of the $\beta$-oxidation cycle and they are generally considered as the rate-limiting enzyme of the sequence $[21,22]$. The wild type possesses five acyl-CoA oxidases (Aox1p to 5) as presented in Fig. 1. Aox $2 p$ seems to play the major role on long-chain acyl-CoA but Aox $4 p$ and Aox $5 p$ are not negligible. On short-chain substrates, Aox3p is the important enzyme with maybe a role of the two other enzymes (Aox4p and Aox $5 \mathrm{p}$ ).

The MTLY36-2P strain $(\Delta p o x 3 \Delta p o x 5)$ lacks two active acyl-CoA oxidases. The deletion of Aox5p results probably in a decrease in the global activity, and that of the short-chain specific Aox3p, in a decrease in the extent of acyl-CoA degradation. The MTLY40-2P strain ( $\triangle$ pox $3 \Delta$ pox4 $\Delta$ pox5) lacks in addition Aox $4 \mathrm{p}$ which has a small activity according to previous results [8]. The lower growth rate of these two mutants compared to the wild type can thus be explained by the lack of Aox $3 p$ and Aox $5 p$ and the observed difference between the two mutant strains suggests a small but significant role for Aox $4 \mathrm{p}$. The difference between the maximal cellular concentration reached by both mutants $\left(2.9-3 \times 10^{7}\right.$ cells $\left./ \mathrm{ml}\right)$ and by the wild type (about $3.5 \times 10^{7}$ cells $/ \mathrm{ml}$ ) could be due to the non utilisation of short-chain substrates by the mutants lacking Aox $3 p$, the short-chain specific enzyme. These growth kinetics results confirm the importance of acyl-CoA oxidases in the growth on lipids.

The construction of a technologically improved strain able to grow at a good rate requires thus the presence of most of the active acyl-CoA oxidases. Some recent works [20] have shown that Aox $2 p$ or Aox $3 p$ were required for a good targeting of acyl-CoA oxidases to peroxisomes explaining thus the lower activity of $\Delta$ pox $2 \Delta$ pox 3 mutants previously observed [8]. All the constructions used in the present study possess Aox $2 p$ or Aox $3 p$. Another factor that may influence the activity is the role of some of the acyl-CoA oxidases in the regulation of the others: the deletion of poxl, pox4 or pox 5 results in an increase in the acyl-CoA oxidase activity. However, this increase is no more detectable when a second pox gene is deleted [8]. As the present constructions have been carried out with the aim of suppressing any activity on short chain substrates, they require the deletion of the short-chain Aoxp encoding gene (POX3). It is thus not possible to utilise the regulation capacity of Aox $1 p$, Aox $4 p$ or Aox $5 p$. Finally, a recent study (this issue, [11]) reported a role of acyl-CoA oxidases in lipids accumulation by $Y$. lipolytica, role which is probably related to a modification in the lipid metabolism. However, these results are still too partial to be used in the lactone production process.

Concluding this part on the growth capacity of the mutant strains of this study, it can be observed that the growth ability is not dramatically altered but the deletion of both pox 5 and pox4 decreases the growth rate of Y. lipolytica. In 


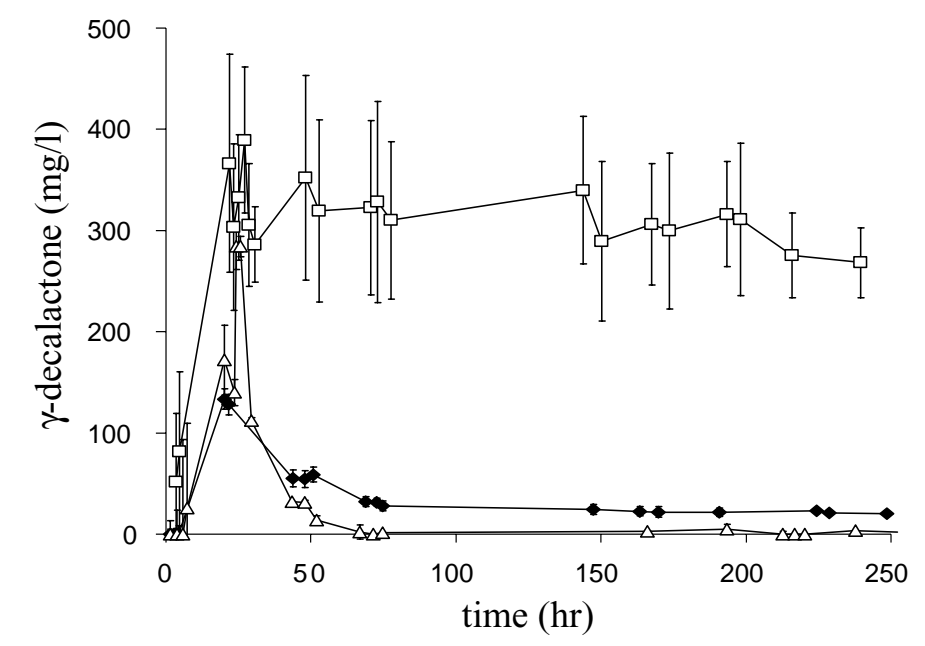

Fig. 3. Production of $\gamma$-decalactone by the wild-type W29 $(\diamond)$ MTLY36-2P $(\triangle)$ and MTLY40-2P ( $\square)$ strains.

the next part, the interest of both deletions for increasing $\gamma$-decalactone production will be investigated.

\subsection{Lactone production by the various strains}

The production of $\gamma$-decalactone by the different strains is shown in Fig. 3. For the wild type, $\gamma$-decalactone appeared in the biotransformation medium after $8-10 \mathrm{~h}$. The concentration increased to about $150 \mathrm{mg} / \mathrm{l}$ after $24 \mathrm{~h}$ and then decreased to $50-60 \mathrm{mg} / \mathrm{l}$ after $40 \mathrm{~h}$ and eventually stabilised at about $20 \mathrm{mg} / \mathrm{l}$. When compared to growth kinetics, the production occurs with a small delay after growth, corresponding probably to the time necessary for the fatty acids to undergo four $\beta$-oxidation cycles, and the degradation (positive difference between the degraded lactone minus the produced lactone) starts right after the end of the growth.

For the MTLY36-2P mutant strain, the production profile (Fig. 3) is very comparable showing without doubt the capacity of this strain to degrade $\gamma$-decalactone contrasting with the results obtained with the previous $\Delta$ pox $3 \Delta$ pox $4 \Delta$ pox 5 construction [14]. A possible explanation for these different results is that the previous construction grew very slowly whereas the new one grows at a rate similar to that of the wild type. As the production of lactone is correlated with the growth phase, a lactone degradation was observed with the new construction after this phase $(20 \mathrm{~h})$ whereas, with the previous construction, the growth phase lasted all along the experiment and the 'degradation phase', in which degradation is higher than production, was never reached. According to the present results, it can be concluded that Aox $4 p$ contributes to the degradation of $\gamma$-decalactone. With our objective to avoid this reaction, it was thus necessary to delete also the Aox $4 \mathrm{p}$ encoding gene (POX4).

For the corresponding construction, MTLY40-2P, the $\gamma$-decalactone production profile is very different (Fig. 3). The production occurs more rapidly, even before the end of the lag growth phase, and increases rapidly reaching values above $300 \mathrm{mg} / \mathrm{l}$ at $20 \mathrm{~h}$ and exhibiting no significant decrease in the next $230 \mathrm{~h}$. These results show not only that this strain is unable to degrade $\gamma$-decalactone in the biotransformation conditions but also that it produces more rapidly, even before growth starts. The absence of degradation can probably not account by itself for this increase and a second mechanism may be implied. The production pathway involves a crossover at the $\mathrm{C} 10$ level (Fig. 1). At this stage, a part of the acyl-CoA lactonises before the next $\beta$-oxidation step, generating $\gamma$-decalactone. But a second part enters the next $\beta$-oxidation cycle without forming the lactone. This phenomenon is not a lactone degradation but it constitutes another leakage in the pathway. By decreasing the acyl-CoA oxidase activity at the $\mathrm{C} 10$ level, this leakage can be lowered and the production can also be significantly increased. Although this strain grows a little more slowly than the wild type, it is very efficient to produce $\gamma$-decalactone in the conditions we used in this study which are not optimised.

\section{Conclusion}

In this study, the role of the various acyl-CoA oxidases of $Y$. lipolytica was specified. It was shown that Aox $4 \mathrm{p}$ was not only Implied in the regulation of the other acyl-CoA oxidases, but also that it exhibited a non negligible activity on the entire spectrum of straight-chain acyl-CoA. Our results confirm the importance of the first step of $\beta$-oxidation in the degradation of lipids by yeast but other steps are still to be studied [11]. From a biotechnological point of view, a strain with only a slightly altered growth and which exhibited no activity on short-chain substrates was constructed. This type of construction is not only of great interest to produce $\gamma$-decalactone but it can also be used for the production of several medium chain-length fatty acidsor alkane-degradation products. 


\section{Acknowledgements}

The authors are thankful to C. Bernard-Rojas for technical help. This work was partly supported by the région Bourgogne.

\section{References}

[1] Y. Waché, M. Aguedo, J.-M. Nicaud, J.-M. Belin, Appl. Microbiol. Biotechnol. 61 (2003) 393.

[2] M. Farbood, B. Willis, Production of $\gamma$-decalactone (1985) WO8301072.

[3] R. Cardillo, C. Fuganti, M. Barbeni, P. Cabella, P. Guerda, G. Allegrone, Procédé de production microbiologique des $\gamma$ - et $\delta$-lactones (1991) EP0412880.

[4] J. Meyer, $\gamma$-Decalactone microbial production from alkyl ricinoleate-by hydrolysis, $\beta$-oxidation, and chemical cyclisation of 4-hydroxy decanoic acid produced for flavouring and perfume (1993) DE4126997.

[5] J.-M. Nicaud, J.-M. Belin, Y. Pagot, A. Endrizzi-Joran, Bioconversion of substrate with microbe auxotrophic for compound in medium deficient in this compound (1996) FR2734843.

[6] C. Ambid, S. Carle, G. De Billerbeck, Method for producing and extracting aromatic compounds (1999) WO9954432.

[7] J. Rabenhorst, I. Gatfield, Process for the production of $\gamma$-decalactone (2000) WO0024920.

[8] H. Wang, M.-T. Le Dall, Y. Waché, C. Laroche, J.-M. Belin, C. Gaillardin, J.-M. Nicaud, J. Bacteriol. 181 (1999) 5140.
[9] Y.S. Luo, H.J. Wang, K.V. Gopalan, D.K. Srivastava, J.-M. Nicaud, T. Chardot, Arch. Biochem. Biophys. 384 (2000) 1.

[10] Y.S. Luo, J.-M. Nicaud, P.P. Van Veldhoven, T. Chardot, Arch. Biochem. Biophys. 407 (2002) 32.

[11] K. Mlíčková, Y. Luo, S. d'Andrea, P. Peè, T. Chardot, J.-M. Nicaud, J. Mol. Catal. B. 28 (2004) 81-85.

[12] Y. Waché, C. Laroche, K. Bergmark, C. Møller-Andersen, M. Aguedo, M.-T. Le Dall, H. Wang, J.-M. Nicaud, J.-M. Belin, Appl. Environ. Microbiol. 66 (2000) 1233.

[13] Y. Waché, M. Aguedo, A. Choquet, I. Gatfield, J.-M. Nicaud, J.-M. Belin, Appl. Environ. Microbiol. 67 (2001) 5700.

[14] Y. Waché, M. Aguedo, M.-T. LeDall, J.-M. Nicaud, J.-M. Belin, J. Mol. Catal. B: Enzym. 19/20 (2002) 347.

[15] S. Mauersberger, H.J. Wang, C. Gaillardin, G. Barth, J.-M. Nicaud, J. Bacteriol. 183 (2001) 5102.

[16] P. Fickers, J.-M. Nicaud, J. Destain, P. Thonart, Appl. Microbiol. Biotechnol. 27 (2003) 27.

[17] J.-M. Nicaud, C. Madzak, P. van den Broek, C. Gysler, P. Duboc, P. Niederberger, C. Gaillardin, FEMS Yeast Res. 2 (2002) 371.

[18] G. Barth, C. Gaillardin, Yarrowia lipolytica: Nonconventional Yeasts in Biotechnology, A Handbook, vol. 1, Springer-Verlag, Berlin, 1996, p. 314.

[19] V.I. Titorenko, R.A. Rachubinski, Nat. Rev. Mol. Cell Biol. 2 (2001) 357.

[20] V.I. Titorenko, J.-M. Nicaud, H. Wang, H. Chan, R.A. Rachubinski, J. Cell Biol. 156 (2002) 481.

[21] N.C. Inestrosa, M. Bronfman, F. Leighton, Biochem. J. 182 (1979) 779 .

[22] N.C. Inestrosa, M. Bronfman, F. Leighton, Biochem. Biophys. Res. Commun. 95 (1980) 7. 